\title{
Reading rocks junior: an exploratory study of an emergent literacy program for children at-risk for learning disabilities
}

\author{
Sierra Holtzheuser ${ }^{1}$, John McNamara ${ }^{1}$, Ashley Short ${ }^{2}$, Chantelle Keay ${ }^{2}$ \\ ${ }^{1}$ Child and Youth Studies, Brock University, St.Catharines, ON, Canada \\ ${ }^{2}$ Learning Disabilities Association of Niagara Region, St.Catharines, ON, Canada
}

\section{Email address:}

sierraholtz@gmail.com (S. Holtzheuser),jmcnamara@brocku.ca (J. McNamara), ldaniagara@cogeco.net (A. Short)

\section{To cite this article:}

Sierra Holtzheuser, John McNamara, Ashley Short, Chantelle Keay. Reading Rocks Junior: An Exploratory Study of an Emergent Literacy Program for Children at-Risk for Learning Disabilities. International Journal of Elementary Education. Vol. 1, No. 1, 2012 , pp. 1-7. doi: $10.11648 /$ j.ijeedu.20120101.11

\begin{abstract}
This paper describes an exploratory study of an emergent literacy program offered by the Learning Disabilities Association of Niagara Region to support young vulnerable readers. The program was designed and offered in response to a community call to support vulnerable children and families. Twenty-three four- to six-year old children participated in the six-week twelve-session program. Children were referred to the program by their schools as they were demonstrating pre-reading skills that placed them at the bottom of their class. The aim of the program was to support children in their emergent literacy skills including phonological and print awareness as well as letter-sound understanding - all emergent literacy skills identified as significant predictors of later reading proficiency.The study adopted a pre- posttest design measuring children's emergent literacy achievement. Results indicate that participating children statistically and clinically increased their literacy skills after participating in the Reading Rocks Junior Program. Research and applied implications of the results are presented.
\end{abstract}

Keywords: Emergent Literacy, Learning Disabilities, Vulnerable Children

\section{Introduction}

Over the past two decades researchers and policy makers have strived to identify and support children with learning disabilities (LD) as early as possible. The short-comings of waiting until children with LD are already lagging behind their peers is well documented (Chatterji, 2006; Dunn, 2007; Louden, Rohl, \& Hopkins, 2008; Siegel, 1989). However, there are a number of psychometric and educational challenges associated with early identification and support. For instance, Scarborough (2001) explores the notion of over-identification when using early screening tools. It appears that an inevitable problem when implementing screening procedures is that screening tools cast a wide net, identifying not only those children at-risk for LD, but children at-risk for reading failure for a number of other reasons (i.e. SES, ESL, etc.). Scarborough (2001) concludes that over-identification is an issue with any kindergarten-screening instrument attempting to identify children at-risk for learning disabilities. However, recognizing this and dealing with it effectively makes the screening process useful. It may be considered that the field is "dealing with it effectively" by accepting the notion that supporting younger at-risk readers assumes that the formal identifications of learning disabilities per se may be clouded. In other words, when working with young vulnerable readers, it is important for stakeholders to understand that it may be difficult to tease out the exact origin of the reading failure. It may be that finding the source of the reading failure is not important, and rather the importance lies in the prevention of reading failure, regardless of cause. This approach has been adopted in the current study. The Learning Disabilities Association of Niagara Region (LDANR), a partner in this study, has begun to build programs that are designed to prevent reading failure - at an age where children are just beginning to demonstrate reading difficulties. To do this, the LDANR has looked towards the notion of emergent literacy.

\section{Emergent Literacy}

Emergent literacy may be defined as the developmental 
period from birth through age six (Justice \& Pullen, 2003; Teale\&Sulzby, 1986). As there has been an increasing focus on literacy among young children, many researchers have agreed that there is not a specific point of time in life that literacy begins, but that at any point, children are in the process of becoming literate (Senechal et al., 2001; Snow, Burns \& Griffin, 1998; Teale\&Sulzby, 1989). Emergent literacy is a relatively recent approach to understanding the development of reading stemming from the recognition that the development of language (oral, reading, writing) is a set of concurrently developing skills that are interrelated (Cabell, Justice, Konold, \&McGuinty, 2010; Teale\&Sulzby, 1986). During the past two decades, the acceptance of the "emergent literacy" perspective by researchers has made an important contribution to our understanding of literacy development (Whitehurst \&Lonigan, 1998). A number of studies centered on emergent literacy have provided evidence that suggests that children are engaging with literacy in a variety of ways during the early years (Campbell, 1995).In general, while preschoolers are not formally reading yet, they are acquiring the skills they will need to read in later years. Therefore, providing the necessary early intervention to improve these skills in children at educational risk is of utmost importance (Simmons et al., 2007).

An important idea around emergent literacy is that not only is preschool an important developmental period, it is also a time when individual differences in emergent literacy begin to become apparent. As such, it provides stakeholders an opportunity to identify and prevent deficits in emergent literacy skills (de Lemos, 2005; Lonigan, 2006). In essence, the developmental period of emergent literacy is a time to consider early identification and prevention programs aimed to support vulnerable children.Research has elucidated that children's emergent literacy achievement in preschool and kindergarten are significant predictors of their later formal reading success (Adams, 1990; Mason \& Allen, 1986; Snow, Burns \& Griffin, 1998). Specifically, emergent literacy skills that are most predictive of later reading include letter-sound understanding, phonological, and print awareness (Snow et al., 1998; Snow, Tabors, Nicholson, \& Kurland, 1994). For instance, in a seminal study of emergent literacy, Lonigan, Burgess \& Anthony (2000) examined the joint and unique predictive significance of emergent literacy skills for post-emergent literacy skills and formal reading in two samples of preschoolers. Results of this study indicated that children's developmental origins of reading skills in kindergarten and grade one can be found in the preschool period. Emergent literacy skills (i.e. phonological sensitivity and letter knowledge) present during preschool reflect highly stable individual differences and have substantial unique predictive relations with later reading abilities. Together, phonological sensitivity and letter knowledge accounted for $54 \%$ of the variance in kindergarten and first-grade children's decoding abilities. These findings highlight the developmental continuity between emergent literacy and later reading from the early preschool period to the early elementary school period.
Emergent literacy is often hypothesized to consist of three essential components; letter-sound understanding, phonological awareness, and print awareness (Adams, 1990; Snow, Burns \& Griffin, 1998; Teale\&Sulzby, 1986). Although all three components are essential to emergent literacy, research has consistently demonstrated that letter-sound understanding is the most significant predictor of later reading (Catts, Fey, Zhang \&Tomblin, 2001; Juel\& Meier, 1999). Letter-sound understanding refers to a child's knowledge of the alphabet and individual letter sounds (Foulin, 2005). A primary element of the reading process is the understanding that words are composed of letters and that these letters correspond to sounds. Research elucidates the predictive ability of letter-sound understanding on later spelling abilities (Pennington, \&Lefly, 2001) and enduring reading achievement throughout elementary school (Blatchford and Plewis, 1990; Juel, 1991). Catts, Fey, Zhang, \&Tomblin (2001) examined the relationship between letter identification in kindergarten and later reading achievement in grade two. A battery of assessments that measured emergent literacy skills such as letter identification and phonological awareness were given to 604 children in kindergarten. Participating children were followed until grade two when they were administered assessments of reading and reading comprehension. Five emergent literacy skills were identified as having predictive ability for reading difficulties in grade two; sentence imitation, deletion task, letter identification, rapid naming and mother education (Catts et al., 2001). However, the most statistically significant predictor of later reading difficulties in grade two was a child's ability to identify their letters and letter sounds in kindergarten.

A second component of emergent literacy is phonological awareness. Phonological awareness refers to an individual's mental operations that make use of the phonological or sound structure of oral language when learning how to decode written language (Anthony \& Francis, 2005; Torgesen, Wagner \&Rashotte, 1994).On its own, phonological awareness has consistently been demonstrated to be a statistically significant predictor of later reading success (Anthony \& Francis, 2005; Anthony \&Lonigan, 2004; Olofsson\&Niedersoe, 1999; Torgesen, et al., 1994). An important element of phonological awareness is one's ability to manipulate phonemes. Activities that demonstrate children's phonological awareness initially may include rhyming tasks, blending tasks, and the ability to match a sound to a particular word (e.g. the sound /b/ is matched with "boy" rather than "toy"). Phonological awareness is a necessary pre-requisite to successful reading as it enables an understanding of how words in our language are represented in print (Torgesen\& Matheson, 2004). Emergent literacy research has more recently begun to study how early phonological awareness intervention programs can support young children who may be struggling with pre-reading skills (Vandervelden\& Siegel, 1997).

The third component of emergent literacy is print awareness.Print awareness refers to environmental print, book awareness and a variety of physical media (Adams, 
1990; Justice \& Ezell, 2001). A child's awareness and sensitivity to print is an important beginning step in the early reading process (Snow, Burns, \& Griffin, 1998). As Adams (1990) points out, while acknowledgement of pictures in books is useful, it is the familiarity of letters that is critical to reading success (Adams, 1990). Young children, from the time of birth, begin to gain print awareness through exposure to print concepts in their environment (Snow et al., 1998). By beginning to understand print, children will begin to discover that reading and writing are ways for them to gain knowledge (Snow et al., 1998).

Although most children learn to read without difficulty, about $10-15 \%$ of children will experience significant difficulties in learning to read text fluently (Snow et al., 1998). There are a number of factors that can affect children's abilities to acquire the fundamentals of fluent reading. Two factors particularly relevant to the current study are cognitive processing problems and socio-economic status (SES).

A primary characteristic of learning disabilities is the notion of phonological processing. Research has been clear in revealing the significant relationship between phonological processing problems and long-lasting reading difficulties (Lonigan, 2006; Torgesen, Wagner, \&Rashotte, 1994). In their longitudinal study of 244 kindergarten children Torgesen et al., (1994) found that individual differences in phonological skills remained stable as children moved from kindergarten to grade two - even when children were receiving early reading instruction. These findings provided support for the conceptualization of phonological skills as stable, permanent individual-difference characteristics that cut across the early school years (Torgesen et al., 1994).One of the practical implications particularly relevant to the current study was the suggestion that phonological variables should be included in assessments that are used to identify children at-risk for reading failure.

Socio-economic status has also been shown to be a significant contributor to long-lasting reading difficulties (Alexander, Entwisle, \& Olson, 2007; Lynch, 2008; Molfese, Modglin\&Molfese, 2003). Lynch (2008) discussed how children from lower SES homes are often at a disadvantage when entering formal schooling compared to their higher SES peers, because of a lack of instruction of important early literacy skills provided in pre-schools serving lower income families. Therefore, children who come from low-income families are at disadvantage when entering formal schooling as a result of fewer opportunities to develop their literacy skills. Specifically, children from lower SES backgrounds have less access to books and less time spent with their caregivers learning literacy skills in the home. Often in lower income families, caregivers spend more time in the workforce resulting in less time spent on literacy activities with their child.Molfese, Modglin and Molfese (2003) studied the influence of environmental factors on intelligence scores by exploring the children's preschool period environment as well as their primary-grade stage and how they are linked to their performance on reading achievement tests.A total of 113 children partici- pated and were assessed at age three and again at age eight through ten on reading achievement and the children's environments (i.e. socioeconomic status and Home Observation for Measurement of the Environment (HOME)). Results showed that for the poor reading group, both the SES and HOME measures were significant predictors of reading achievement scores at eight years of age (Molfese et al., 2003). Also, SES and HOME total scores were predictive of reading scores at eight years and word attack scores at ten years of age for all participating children. In this study, participating children were from two lower-income communities and as such SES may have played a factor in children's reading difficulties.

\section{The Current Study}

The current study examined the efficacy of an emergent literacy program designed to support young children at-risk for reading difficulties. The emergent literacy intervention investigated here combined an embedded and explicit approach to enhancing emergent literacy skills in young vulnerable readers. The intervention involved children in meaningful literacy-based interactions both individually and in small groups. The program lesson plans focused on providing opportunities for explicit teaching of emergent literacy skills. The specific skills delivered in the program included letter-sound understanding, and phonological and print awareness - foundational emergent literacy skills recommended by the National Reading Panel (2000).

The program, Reading Rocks Junior (RR-J), was offered by the Learning Disabilities Association of Niagara Region to four- to six-year old children living in two lower socio-economic communities in a mid-sized Southern Ontario city. Each program session began with modeled reading, where a trained facilitator read aloud to the children, to demonstrate fluency and expressivity. Children were then broken up into small groups where they rotated through stations that targeted the above-mentioned skills as well as sight word vocabulary and phonetic principles. At each station children worked on emergent literacy skills they had yet to master through direct and explicit instruction, and interactive games to consolidate their learning. At the phonics station for example, children worked on the letter names and sounds they had yet to master through explicit instruction of the principle followed by various interactive lessons. At the sight word station children were exposed to early sight words (i.e. the, at, you, my) through engaging games and stories. Research indicates the importance of not only using small groups but also providing struggling children with one-to-one support. Specifically, one-to-one support allows each child to work at their own pace and on skills that are not being mastered in the small group environment. Therefore, while children rotated through the work-stations trained tutors worked individually with children to target areas where they required extra assistance. Throughout the program, families were provided with books and materials to support the implementation of the skills and 
strategies that each child had learned in the program. These materials were complimentary to all participating families.

\section{Methodology}

\subsection{Participants}

A total of 23 four- to six-year old children participated in the current study. The mean age of children was 67 months and there were 11 boys and 12 girls. Study eligibility was determined based on school-based emergent literacy achievement and the absence of co-morbid disorders or low-incidence disabilities (i.e. severe intellectual impairments). Children were either referred by their principal, classroom teacher, or self-referred by their primary caregiver All participating children were living in two lower socioeconomic status neighborhoods in Southern Ontario. Each neighborhood was identified as high-needs based on the socio-economic status index measured by the Regional Early Years Neighborhood Mapping Tool. The Reading Rocks Junior program was offered at no cost at two school locations within the two neighborhoods.

\subsection{Measures}

The study used a pre- posttest design where participating children were administered four assessments on the first and last evening of the program. The measures used in this study were adopted based on their theoretical underpinnings associated with the concept of emergent literacy. As described in the previous section, emergent literacy is thought to consist of phonological and print awareness as well as letter-sound understanding. The following measures reflect these skills.

\subsubsection{Test of Preschool Early Literacy (TOPEL)}

The Test of Preschool Early Literacy (Lonigan, et al., 2007) is a theoretically sound instrument for identifying pre-schoolers who are at risk for literacy problems, therefore, allowing early intervention. The TOPEL provides valid and reliable raw and standard scores. The normative sample consists of 842 preschool-aged children (three to five years). The current study used two TOPEL subtests - print knowledge (36 items) and phonological awareness (27 items).

\subsubsection{Print Knowledge}

This subtest has 36 items and measures alphabet knowledge and early knowledge about written language conventions and form. The child was asked to identify letters and written words, point to specific letters, names specific letters, identify letters associated with specific sounds, and to say the sounds associated with specific letters. Reliability coefficients for the TOPEL Print Knowledge for four-year old children was $(\mathrm{a}=96)$.

\subsubsection{Phonological Awareness}

This subtest has 27 items and measures word elision and blending abilities. The child was asked to say a word, and then say what was left after dropping out specific sounds (elision) for the first 12 items. The child was asked to listen to separate sounds and combine them to form a word (blending) for the remaining 15 items. Reliability coefficients for the TOPEL Print Knowledge for four-year old children was $(\mathrm{a}=88)$.

\subsubsection{Letter Recognition}

Letter recognition clearly taps into something of critical importance in early reading (Juel\& Meier, 1999). The major task of letter naming is mapping a visual symbol to a phonetic representation.Therefore, for this task children were shown all twenty-six lower-case letters and twenty-six upper-case letters of the English alphabet and asked to give the letter name. Students were scored as correct if they responded with the appropriate letter name. The total maximum score for Letter Recognition was 54.

\subsubsection{Letter-Sound Correspondence}

Letter-sound tasks requires associating symbols with discrete sounds, which may be more challenging, because it requires isolating individual phonemes. Research has demonstrated that this skill has a significant causal effect on subsequent development of phonological skills (Juel\& Meier, 1999). For this task students were shown lower-case letters and asked to give the corresponding sound. If students responded with a letter's corresponding soft sound (ex. /c/ as in race), they were prompted to think about another sound. The target sound was the hard consonant or short vowel sound. Students were scored as correct if they responded with the appropriate letter sound. The total maximum score for Letter-Sound Correspondence was 26.

\section{Results}

We adopted a pre-test posttest design to determine if children demonstrated statistically significant improvements from participating in the program. Pre- and posttest means and standard deviations are illustrated in Table 1. Paired sample t-tests were computed for all measures of emergent literacy. In general, results indicated a statistically significant increase for all measures. Specifically, children demonstrated a statistically significant increase in their TOPEL print awareness, $\mathrm{t}(23)=-3.61, \mathrm{p}<.005$, and TOPEL phonological awareness, $\mathrm{t}(23)=-3.80, \mathrm{p}<.001$. Children also demonstrated a statistically significant increase in letter recognition, $\mathrm{t}(23)=-4.30, \mathrm{p}<.001$, and letter-sound understanding, $\mathrm{t}(23)=-3.84, \mathrm{p}<.001$.

Although pre- and posttest analyses revealed statistically significant increases for all measures, these results fail to demonstrate whether the increases are clinically significant. In other words, it is important to determine whether the increases made by participating children are within achievement levels of typically-achieving four to six year old children. To do this, we compared mean pre- and posttest TOPEL scores to percentile rank scores reported in the TOPEL technical data. At the pre-test, children had a TOPEL print awareness mean score of 27.0 converting to a percentile rank score of 47 . Post-test mean scores for print 
awareness were 31.0 corresponding to a percentile rank score of 65 . These results indicate that participating children not only demonstrated a statistically significant increase as a result of the program, but that these increases were within achievement levels of typically achieving four to six year old children. A similar trend emerged for TOPEL phonological awareness. Pre-test mean scores for phonological awareness were 18.7 converting to a percentile rank score of
30. Post-test mean scores for phonological awareness were 21.8 corresponding to a percentile rank score of 61 . These results indicate that participating children demonstrated both statistically significant and clinically significant increases, whereby posttest scores were within achievement levels commensurate with typically-achieving four- to six-year old children. Pre- and posttest clinical gains are demonstrated in Table 1.

Table 1. Means, standard deviations, and paired t-test analyses for TOPEL and Letter-Sound.

\begin{tabular}{|c|c|c|c|c|c|c|c|c|}
\hline & \multicolumn{3}{|c|}{ Pre-test } & \multicolumn{5}{|c|}{ Post-test } \\
\hline & Mean & SD & Percentile Rank & Mean & SD & Percentile Rank & $t$-value & Significance \\
\hline TOPEL print awareness (36) & 27.0 & 8.7 & 47 & 31.0 & 5.3 & 65 & -3.61 & .005 \\
\hline $\begin{array}{l}\text { TOPEL } \\
\text { phonological awareness (27) }\end{array}$ & 18.7 & 5.9 & 30 & 21.8 & 4.6 & 53 & -3.80 & .001 \\
\hline Letter Recognition (54) & 37.8 & 16.4 & $\mathrm{~N} / \mathrm{A}$ & 45.3 & 10.4 & $\mathrm{~N} / \mathrm{A}$ & -4.30 & .001 \\
\hline $\begin{array}{l}\text { Letter-Sound } \\
\text { Correspondence (26) }\end{array}$ & 13.0 & 9.2 & N/A & 17.3 & 6.6 & N/A & -3.84 & .001 \\
\hline
\end{tabular}

Clinically significant analyses were not possible to conduct for letter recognition and letter-sound correspondence, as there are no established benchmarks for kindergarten letter knowledge. It is important to note, that the largest statistical gain was letter recognition. Mean scores for letter recognition increased from 37.8 to 45.3 after participating in the program. This trend was not as large for letter-sound correspondence (increased from 13.0 to 17.3); however this skill is developmentally more complicated for children just completing their junior kindergarten year.

\section{Discussion}

The aim of this exploratory study was to examine the efficacy of an emergent literacy intervention for four- to six-year old children who were at-risk for reading failure. The program, Reading Rocks Junior, was offered by the Learning Disabilities Association of Niagara Region in response to a regional call to support young vulnerable children. The program was offered in two lower-income communities for twelve sessions over six weeks. The Reading Rocks Junior program emphasized emergent literacy skills including letter-recognition, letter-sound understanding, print awareness and phonological awareness. In general, the results were encouraging. Participating children demonstrated statistically and clinically significant mean score gains in all four emergent literacy skill areas. Specifically, after participating in the program children were achieving at emergent literacy levels that were commensurate with typically achieving four- to six-year old children. This study holds a number of important implications. First, the study was an applied research exploration of emergent literacy. Over the past decade, research has begun to elucidate the powerful effect that emergent literacy intervention has on children's future reading success (Lonigan, Burgess, $\&$ Anthony, 2000). Snow, Burns and Griffin (1998) suggest that young children demonstrating weak emergent literacy skills should be supported before they begin formal literacy training.

The second implication stemming from the current study reflects research demonstrating that children from low-income homes are particularly at-risk for underdeveloped emergent literacy skills. Following this, the current study was designed to support early reading difficulties within two lower SES communities. This is particularly important as programming for vulnerable children is often inaccessible to the families that are in particular need of such programming. By hosting the Reading Rocks Junior program within two neighborhood schools, families could easily access the program without barriers such as transportation. Also related to the issue of accessibility, is cost. Reading Rocks Junior was offered at no cost to participating families. It is important that factors such as accessibility and cost are considered when designing programs aimed as supporting vulnerable children and families. A third implication centers on the idea that Reading Rocks Junior adopted an embedded and explicit instructional approach that emphasized specific skills building. The notion of emergent literacy holds that literacy begins prior to formal schooling. Skills such as letter-recognition, letter-sound understanding and phonological awareness are shown to be significant predictors of future reading. Models of emergent literacy dictate that these skills develop from birth onwards. Following this, literacy programs should consider the developmental period of birth to age six. Finally, the program included an embedded and explicit instructional approach in small groups and individually with trained facilitators. Two decades of research has pointed to the importance of expli- 
citly emphasizing emergent literacy skills within instructional programs.

There are a number of limitations and future directions associated with the current study. First, is the relatively small sample size.The purpose of the current study was to explore the effectiveness of an emergent literacy program in order to specify the most important variables related to developing an effective program. By limiting the sample size, the research team was able to provide small group and individual attention to each participating child - an important tenet of effective remedial instruction. The smaller sample size also enabled the research team to closely monitor the achievement of participating children. However, to further establish the generalizability of such a study, it would be prudent for future research to include a larger sample of participants. The second limitation was the lack of control group. To firmly establish the effectiveness of such a program it would be important to compare the gains of the program group to the achievement levels of a non-program group. To counteract this concern, the current study adopted a research protocol whereby achievement gains were computed as percentile rank scores and compared to norm-referenced data.A third limitation is that the sustainability of the achievement gains was not measured. It would be important to study the long-term impact of similar programs.

In general, the results of this study indicate the importance of providing vulnerable children with accessible emergent literacy programs. Participating children not only made statistically significant improvements in all areas of emergent literacy, but improved to a level commensurate with their typically-achieving peers. By providing this type of programming, vulnerable children will have the tools to develop into proficient readers.

\section{Acknowledgements}

The research team is grateful to the staff, volunteers, and research assistants from the Learning Disabilities Association of the Niagara Region. This research was supported by a grant from the Niagara Prosperity Initiative.

\section{References}

[1] Adams, M. J. (1990). Beginning to read: Thinking and learning about print. Cambridge, MA:The MIT Press.

[2] Alexander, K., Entwisle, D., \& Olson, L. (2007). Lasting consequences of the summer learning gap. American Sociological Review, 72, 167-180.

[3] Anthony, J. L., \& Francis, D. J. (2005). Development of phonological awareness. Current Directions in Psychological Science, 14, 255-259.

[4] Anthony, J. L., \&Lonigan, C. J. (2004). Nature of phonological sensitivity: Converging evidence from four studies of preschool and early grade-school children. Journal of Educational Psychology, 96, 43-55.

[5] Blatchford, P., \&Plewis, L. (1990). Pre-schoolreading-related skills and later reading achievement: Further evidence. British Educational Research Journal, 16, 425-428.

[6] Cabell, S. Q., Justice, L. M., Konold, T. R., \&McGinty, A. S. (2011). Profiles of emergent literacy skills among preschool children who are at risk for academic difficulties. Early Childhood Research Quarterly, 26, 1-14.

[7] Campbell, R. (1995). Reading in the early years handbook. Buckingham: Open University Press.

[8] Catts, H. W., Fey, M. E., Zhang, X., \&Tomblin, J. B. (2001). Estimating the risk of future reading difficulties in kindergarten children: A research-based model and its clinical implications. Language, Speech, and Hearing Services in Schools, 32, 38-50.

[9] Chatterji, M. (2006). Reading achievement gaps, correlates, and moderators of early reading achievement: Evidence from the Early Childhood Longitudinal Study (ECLS) kindergarten to first grade sample. Journal of Educational Psychology, 98, 489-507.

[10] deLemos, M. (2005). Effective strategies for the teaching of reading: What works and why. Australian Journal of Learning Disabilities, 10, 11-17.

[11] Dunn, M. W. (2007). Diagnosing reading disability: Reading recovery as a component of a response-to-intervention assessment method. Learning Disabilities: A Contemporary Journal, 5, 31-47.

[12] Foulin, J. N. (2005). Why is letter-name knowledge such a good predictor of learning to read? Reading and Writing, 18, 129-155.

[13] Juel, C. (1991). Cross-age tutoring between student athletes and at-risk children. The Reading Teacher, 45, 178-186.

[14] Juel, C. \& Meier, J. (1999). Teaching content and form through balanced instruction. Teaching and Change, 6, 182-196.

[15] Justice, L. M., \& Pullen, P. C. (2003). Promising interventions for promoting emergent literacy skills: Three evidence-based approaches. Topics in Early Childhood Special Education, 23, 99-113.

[16] Lonigan, C. J. (2006). Conceptualizing phonological processing skills in prereaders. In D. K. Dickinson \& S. B. Neuman (Eds.), Handbook of Early Literacy Research (Col. 2, pp. 77-110). New York: Guilford.

[17] Lonigan, C., Burgess, S. R., \& Anthony, J. L. (2000). Development of emergent literacy and early reading skills in preschool children: Evidence from a latent-variable longitudinal study. Developmental Psychology, 36, 596-613.

[18] Lonigan, C., Wagner, R., Torgesen, J. \&Rashotte, C. (2007). Test of preschool early literacy. PRO-ED, Inc. Austin, TX.

[19] Louden, W., Rohl, M., \& Hopkins, S. (2008). Teaching for growth: Effective teaching of literacy and numeracy. Perth, WA: Graduate School of Education, University of Western Australia.

[20] Lynch, J. (2008). Engagement with print: Low-income families and head start children. Journal of Early Childhood Literacy, 8 (2), 151- 175.

[21] Mason, J. M., \& Allen, J. (1986). A review of emergent literacy with implications for research and practice in reading. 
In E. Rothkopf (Ed.), Review of Research in Education, 13, 3-47. Washington, DC: American Educational Research Association.

[22] Molfese, V, Modglin, A, \&Molfese, D. (2003). The Role of environment in the development of reading skills: A longitudinal study of preschool and school-age measures. Journal of Learning Disabilities, 36(1), 59-67.

[23] Olofsson, A, \&Niedersoe, J. (1999). Early language development and kindergarten phonologicalawareness as predictors of reading problems: from 3 to 11 years of age. Journal of Learning Disabilities, 32, 464-472.

[24] Pennington, B. F., \&Lefly, D. L. (2001). Early reading development in children at-risk for dyslexia. Child Development, 72, 816-833.

[25] Phillips, B.M., Clancy-Menchetti, J., Lonigan, C.J. (2008).Successful phonological awareness instruction with preschool children: Lessons from the classroom. Topics in Early Childhood Special Education, 28, 3-17.

[26] Pullen, P., \& Justice, L. M. (2003). Enhancing phonological awareness, print awareness, and oral language skills in preschool children. Intervention in School and Clinic, 39, 87-98.

[27] Scarborough, H. S. (2001). Connecting early language and literacy to later reading (dis)abilities: Evidence, theory, and practice. In S. Neuman\& D. Dickinson (Eds.), Handbook for research in early literacy (pp. 97-110). New York: Guilford Press.

[28] Senechal, M., LeFevre, J., Thomas, E. M., \& Daley, K. E. (1998). Differential effects of home literacy experiences on the development of oral and written language. Reading Research Quarterly, 33, 96-116.
[29] Siegel, L. (1989). IQ is irrelevant to the definition of learning Disabilities. Journal of Learning Disabilities, 22(8), 469-478.

[30] Simmons, D., Kame'enui, E., Harn, B., Coyne, M., Stoolmiller, M., Santoro, L., et al. (2007). Attributes of effective and efficient kindergarten reading intervention: An examination of instructional time and design specificity. Journal of Learning Disabilities, 40, 331-347.

[31] Snow, C. E., Burns, M. S., \& Griffin, P. (1998). Preventing reading difficulties in young children. Washington, DC: National Academy Press.

[32] Snow, E., Tabors, P. O., Nicolson, P. A., \& Kurland, B. F. (1995). SHELL: Oral language and early literacy skills in kindergarten first grade children. Journal of Research in Childhood Education, 10, 37-48.

[33] Teale, W. H., \&Sulzby, E. (Eds.). (1986). Emergent literacy: Reading and writing. Westport, CT: Ablex Publishing Corporation.

[34] Torgesen, J. K., \& Matheson, P. G. (2000). A basic guide to understand, assessing and teaching phonological awareness. Austin, TX: Pro-Ed.

[35] Torgesen, J. K., Wagner, R, \&Rashotte, C. (1994). Longitudinal studies of phonological processing and reading. Journal of Learning Disabilities, 27(5), 276-286.

[36] Vandervelden, M.C. \& Siegel, L.S. (1997). Teaching phonological processing skills in earlyliteracy: A developmental approach. Learning Disabilities Quarterly, 20, 63-81.

[37] Whitehurst, G. J., \&Lonigan, C. J. (1998). Child development and emergent literacy. Child Development, 69, $848-872$. 